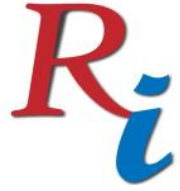

Asia Proceedings of Social Sciences

(APSS)

www.readersinsight.net/APSS

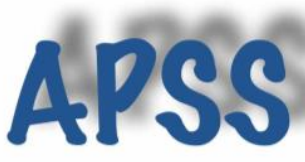

\title{
THE EMPLOYMENT OF LEARNING STRATEGIES IN LEARNING ENGINEERING TERMINOLOGY AMONG ENGINEERING UNDERGRADUATES
}

\section{Amri Muaz Azmimurad*}

Centre for Modern Languages and Human Sciences

Universiti Malaysia Pahang

Malaysia

\section{Najah Osman}

Centre for Modern Languages and Human Sciences

Universiti Malaysia Pahang

Malaysia

*Corrosponding author's Email: amrimuazz@gmail.com

Author's Biography

Picture

The author holds a Bachelor of Arts (Hons.) English for Professionals from Universiti Sains Malaysia and is currently pursuing his master's degree in English Language and Professional Communication. He has one year of experience in teaching the English language at several colleges and universities. His research thrust is English for Specific Purposes in which he is focusing on technical vocabulary. He has received several awards and has

joined various research competitions.

Peer-review under responsibility of $3^{\text {rd }}$ Asia International Multidisciplanry Conference 2019 editorial board (http://www.utm.my/asia/our-team/) (C) 2019 Published by Readers Insight Publisher, lat 306 Savoy Residencia, Block 3 F11/1,44000 Islamabad. Pakistan,

info@readersinsight.net

This is an open access article under the CC BY-NC-ND license (http://creativecommons.org/licenses/by-nc-nd/4.0/). 


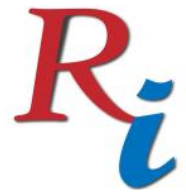

Asia Proceedings of Social Sciences

(APSS)

www.readersinsight.net/APSS

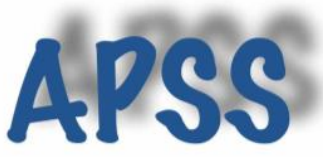

\section{Rese a r ch H i g h I igh t s}

This research reports on a mixed method study with the aim to discover the employment of vocabulary learning strategies by students majoring in engineering course in learning technical vocabulary which is in this context, the engineering terminologies. This research adopted Explicit Vocabulary Learning Theory by Ellis (1994) which proposed that there are usage of learning strategies in the process of learning word meanings. Five vocabulary learning strategies taxonomies were employed in this study which were developed by Schmitt (1994) which are determination, social, memory, cognitive and metacognitive strategies. Each taxonomy has a few strategies that are developed specifically according to the type of strategies used. All five taxonomies of vocabulary learning strategies were compared to the students' field of study, year of study and English proficiency level. Previous studies highlighted that there were differences found in the use of strategies among learners in comparison to their characteristics.

\section{Research Objectives}

Current research focuses on engineering terminology and vocabulary learning strategies. Engineering terminologies or words fall under technical vocabulary which has a higher complexity in comparison to general and academic vocabulary. This type of vocabulary is very field-specific and mostly used and understood among people working in the specific industry or work field. This research aims to discover the most and least frequently used vocabulary learning strategies among engineering undegraduates in learning technical vocabulary. Another aims of this study are to explore the differences in vocabulary learning strategies used according to the students' characteristics such as the field they are majoring in, their year of study and also their English proficiency level.

\section{Methodology}

This research employed mixed method paradigm as both quantitative and qualitative approach were used in collecting the data. Explanatory research design was used as the qualitative data that was collected after the quantitative data collection was complete was used to answer and give further explanation towards the results from quantitative data. The instruments that were employed in this research were a vocabulary learning strategies questionnaire and a semistructured interview. Both of the instruments were adapted from previous research. The vocabulary learning strategies questionnaire was adapted from Puagsang (2017) and the pilot test result showed that the questionnaire is reliable to be used in this research. The questions in the in the interview were adapted from Fan (2015) was validated using Interview Protocol Refinement process developed by Castillo-Montoya (2016). The interview was one-to-one semi-structured interview. 150 students majoring in engineering from five different clusters participated in this study and 12 students volunteered to be participating in the interview sessions. The five clusters involved in this study represents the main engineering clusters available in Malaysia. The population of this study is university students while the sample frame is engineering students in third and fourth year of study.

\section{Results}

This research found that the engineering undergraduates employed vocabulary learning strategies in their process of learning technical vocabulary which is engineering terminology. However, it was found that they have their own preferences in choosing strategies and only 


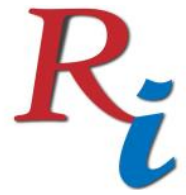

\section{Asia Proceedings of Social Sciences \\ (APSS) \\ www.readersinsight.net/APSS}

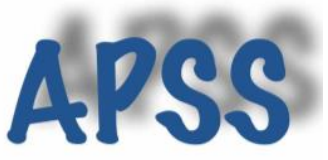

employed certain strategies from the five taxonomies. It was found that watching and listening to English media such as songs and videos was the most popular and most frequently strategy from metacognitive strategies taxonomy. The least popular and least frequently used strategy which was to keep a vocabulary notebook comes from cognitive strategies taxonomy. Among the ten most frequently used vocabulary learning strategies, six of the strategies belong to metacognitive strategies taxonomy. Among the ten least frequently used vocabulary learning strategies, strategies from social and cognitive strategies taxonomies contribute six strategies with three from each taxonomy. The result shows that there were no significant differences found in the employment of vocabulary learning strategies according to field of study and English language proficiency. However, there were a significant difference found in the employment of vocabulary learning strategies according to year of study.

\section{Findings}

This research found out that engineering students employ strategies mostly from metacognitive strategies taxonomy which is in line with studies by Ahmad et al. (2016) and Leilei (2016). However, this findings contradict to the findings reported by Puagsang (2017) which claimed that the most frequently used strategies were from social strategies taxonomy. The most frequently used strategy which was watching and listening to English media implied that these students prefer strategies that has some entertainment element. The students least preferred strategy was to keep a vocabulary notebook which suggested that it might be a hassle for these students to carry a notebook especially a vocabulary notebook with them all the time.

\section{References}

Ahmad, H., Yunus, M.M., Hasan, N.H., 2016. English Vocabulary Size and Vocabulary Learning Strategies of UiTM Pre- Diploma Students Haryati Ahmad 150-170.

Castillo-Montoya, M., 2016. Preparing for Interview Research: The Interview Protocol Refinement Framework. Qual. Rep. 21, 811-831.

Ellis, N.C., 1994. Vocabulary acquisition: The implicit ins and outs of explicit cognitive mediation, in: Implicit and Explicit Learning of Languages. pp. 211-282.

Fan, N., 2015. A Study of Vocabulary Knowledge and Vocabulary Learning Strategies of Chinese EFL Learners.

Leilei, L.I.U., 2016. A Study of English Vocabulary Learning Strategies of Non-English Major College Students. Stud. Lit. Lang. 13, 50-56.

Puagsang, N., 2017. Vocational Students' Use of Vocabulary Learning Strategies. Pasaa Parit. J. 32, 146-165.

Schmitt, N., 1994. Vocabulary Testing: Questions for Testy Development with Six Examples of Tests of Vocabulary Size and Depth. Thai TESOL Bull. 6, 9-16. 